\title{
Drive System Design for a Permanent Magnet Motor with Independent Excitation Winding for an Electric Bicycle
}

\author{
Young-Dae Son ${ }^{\dagger}$ and Gyu-Hong Kang*
}

\begin{abstract}
This paper presents the implementation and characteristic analysis of a drive system for a three-phase permanent magnet motor with independent excitation winding that is applicable for electric bicycles. The design features improves the phase current waveform, output power, and torque by using advance angle control. This adjusts the phase angle of each phase current in relation to back EMF. In addition, a DC-side PI current control is performed through PWM generation circuit using a low-cost one-chip microcontroller and a CPLD chip, resulting in reduced system costs. Finally, the validity of this control scheme for driving electric bicycles and output/torque improvement characteristics are verified through analysis and experimental results.
\end{abstract}

Keywords: IEWPM, Electric Bicycle, PI current controller, CPLD, Phase advance angle

\section{Introduction}

Recently, environment-friendly bicycle markets adopting electric motor have broadened its application in various fields due to environmental issues and rising oil prices. Korea, aiming to become one of the world's top electric bicycle producers in 5 years, along with China, Europe, Japan, Taiwan, and the US, are paying considerable attention to these markets. Application targets, areas with a growing need for environment-friendly personal transport, include those used as guidance bicycles for racing; as law enforcement service vehicles for municipal parking and traffic police; as viewing transporters in parks, leisure, shopping; and as commuter bicycles. The demand for electric bicycle is increasing because of its many advantages, such as lower energy cost per moving distance (1\%-2\% compared to automobile) and lower insurance premiums, the non-requirement for driver's licenses and registration taxes, reduced parking charges, improvement in traffic flow, and environment-friendly and better health from exercise. Not only in China (occupying $40 \%$ of the worldwide electric bicycle market), but also $90 \%$ of global manufacturing companies, use the hub-type direct-driving equipment that mounts the outer-rotor pancake-type motor on the center of wheel. This direct driving system, however, wastes too much energy during climbing or startup, as well as induces disrupting balance when the motor is mounted on the front wheel. In this paper, the proposed system mounts the driving equipment into a built-in motor on the middle of the bicycle near the pedal, reducing battery consumption during startup or climbing, thereby extending battery life and mileage. In addition, the spoke-type permanent magnet

\footnotetext{
$\dagger$ Corresponding Author: Dept. of Electronic Engineering, Dongseo University, Busan, Korea. (ydson@gdsu.dongseo.ac.kr)

* Electric and Electronic Research Division, Korea Marine Equipment Research Institute (KOMERI), Busan, Korea. (kang@komeri.re.kr)

Received: May 10, 2010; Accepted: June 29, 2010
}

motor proposed in this paper does not have any interconnected winding configuration, but an independent winding configuration between phases, enabling it to easily increase phase numbers and achieve higher degree of freedom in terms of controller design. The small, lightweight motor is capable of sustaining high efficiency at broad speed ranges and driving without the arbitrary phase, as opposed to the conventional Y-connection brushless direct current (BLDC) motors [1], [4] frequently used as electric bicycle motors. Specifically, it can extend the phase number easily from 3phase to multi-phase, such as in switched reluctance motors (SRM), as well as increase the electromagnetic torque per unit volume using spoke-type permanent magnets like in BLDC motors. In addition, it presents other various advantages compared with the others, such as high torque at low speeds and more power at high speeds, high efficiency at broad speed ranges, quick response and reversibility, and low manufacturing costs resulting from excitation width and advance angle control by using two position sensors per phase. In addition, as it is mechanically rigid at ultrahigh speeds and provides magnetic flux concentration from the bar-type magnets embedded in the rotor core, smaller motors with low manufacturing costs can be produced, unlike with other motors utilizing the same type of magnets. As the phase currents of the motor cannot be increased instantaneously to the rated level due to inductance of stator windings, it has lesser torque and slower speed response during high speed driving. Consequently, improvements in the phase currents is essential for industry applications, which require broad speed control range.

This paper applies advance angle control [2], [3] in order adjusts the current lead phase angle to $30^{\circ}$ in relation to back EMF. In effect, it improves the phase current and subsequently enhances output torque and speed response. This paper also proposes the implementation of a drive control system for electric bicycles by applying advance angle control, DC-side PI current control, pulse width modulator (PWM) logic circuit design using low-cost one-chip micro- 
controller and complex programmable logic device (CPLD), and spoke-type permanent magnet motor. The present work confirmed the validity of the said control system through analysis and experimental results.

\section{IEWPM Motor Drive System}

\subsection{Features of the IEWPM Motor}

In this paper, a new spoke-type independent excitation winding permanent magnet (IEWPM) motor that can replace the conventional Y-connection BLDC motor or SRM is applied to a current electric bicycle system. It has both the independent excitation winding in SRMs and the rare earth permanent magnets in BLDC motors; both are incorporated into the design of the drive control system of the electric bicycle. Fig. 1 shows the basic structure of IEWPM motor [5] and the driving inverter.

As shown in Fig. 1(b), the driving inverter is composed of 12 power switches. It has independent windings (i.e., no connection points between each motor phase) and uses a two-phase excitation method, which conducts two phases in each conduction interval. The inductance variation of the IEWPM motor, voltage, and torque equation for calculating instantaneous currents of the a-phase is as follows:

$$
\begin{gathered}
V_{a}=R i_{a}+\frac{d}{d t}\left[L_{a}(\theta)+M(\theta)\right] i_{a}+e_{a} \\
\frac{d i_{a}}{d t}=\frac{1}{L_{a}(\theta)+M(\theta)}\left[V_{a}-e_{a}\right] \\
T_{a}=\frac{e_{a} i_{a}}{\omega_{m}}+\frac{1}{2} i_{a}{ }^{2} \frac{\partial L_{a}(\theta)}{\partial \theta}
\end{gathered}
$$

where $V_{a}, e_{a}, i_{a}, L_{a}$, and $T_{a}$ are the voltage, back EMF, current, inductance, and torque of the a-phase, respectively.
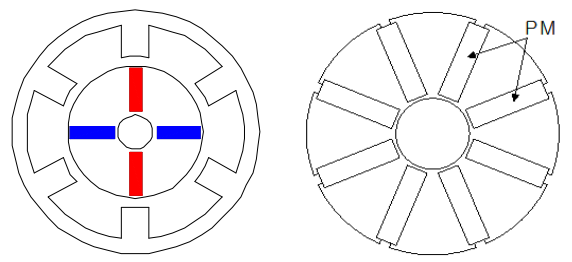

(a) The basic structure of IEWPM motor

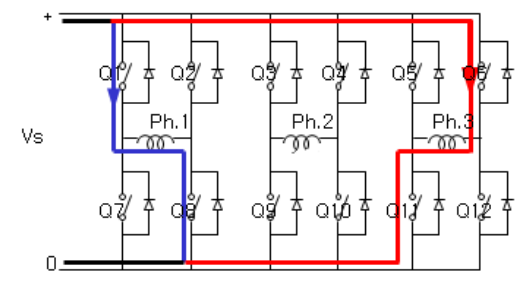

(b) Driving inverter with 12 switches

Fig. 1. Structure of IEWPM motor and driving inverter.
In addition, $M, \omega_{m}$, and $\theta$ are the mutual inductance, rotor speed, and rotor position, respectively. Spoke-type IEWPM motor has inductance variation generating reluctance torque according to rotor position, as determined by the second term of Equation (3). For this reason, it results in an inordinate ripple of phase current, torque ripple, and vibration. Therefore, a waveform improvement of phase currents by means of advance angle and excitation width control is needed to reduce torque ripple. Using the selected advance angle and excitation width as variables to improve the current waveform of IEWPM motor, it needs an exact current dynamic analysis, combining FEM and phase voltage equation for optimal motor driving. This paper performed characteristic analysis of the spoke-type IEWPM motor analyzed from FEM and voltage equation. Table 1 shows the specifications of the proposed motor. Fig. 2 illustrates the equi-potential distribution.

Fig. 3 shows the no-load back EMF characteristics at 500 rpm, while Fig. 4 shows the torque characteristics when a square wave of current is applied to the system. As shown in Figs. 3 and 4, slot harmonic components are included, resulting in a very large harmonic component with torque characteristics.

Table 1. Motor specifications

\begin{tabular}{c|c|c|c}
\hline Parameters & Value & Parameters & Value \\
\hline Poles & 8 & $\begin{array}{c}\text { Residual magnetic } \\
\text { flux density [T] }\end{array}$ & 1.25 \\
\hline Slot & 36 & Output [W] & 600 \\
\hline $\begin{array}{c}\text { Series conductor } \\
\text { per phase }\end{array}$ & 72 & $\begin{array}{c}\text { Axis-direction } \\
\text { length [mm] }\end{array}$ & 85 \\
\hline $\begin{array}{c}\text { Conductor } \\
\text { diameter [mm] }\end{array}$ & 0.7 & Phase resistance [S] & 0.054 \\
\hline Rotor diameter [mm] & 125 & Phase inductance [mH] & 0.243 \\
\hline
\end{tabular}

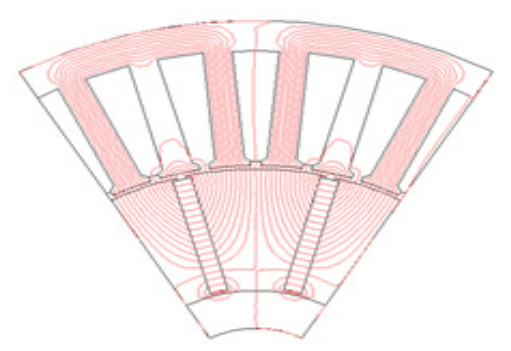

Fig. 2. Equi-potential distribution.

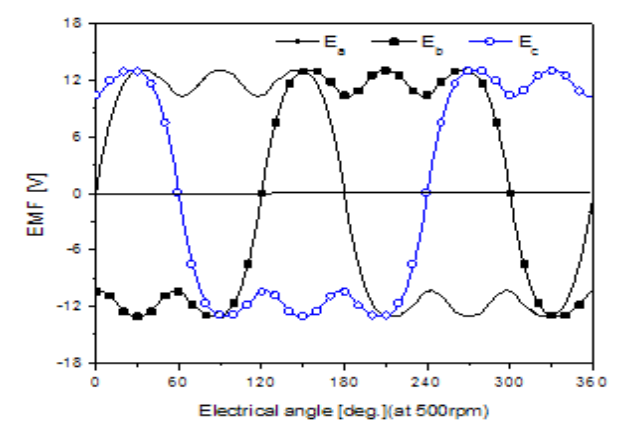

Fig. 3. Back EMF characteristic at no load (500 rpm). 


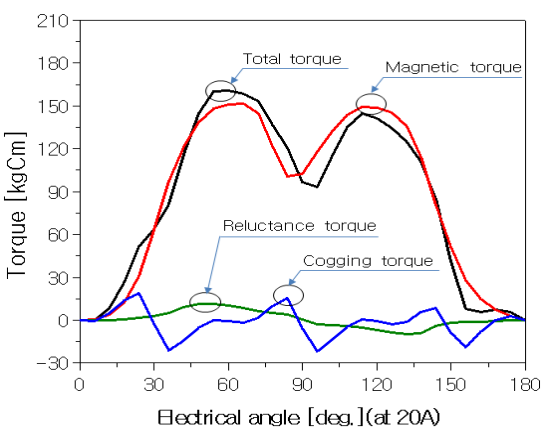

Fig. 4. Torque characteristic.

Each phase of the spoke-type IEWPM motor is supplied separately, and it could instantaneously compute the current characteristics by using the one-phase voltage equation. It could also derive the current waveform for advance angle control. Fig. 5 represents the waveform of phase currents for an advance angle control. Fig. 6 shows the phase current, back EMF, and output power for a $30^{\circ}$ advance angle.

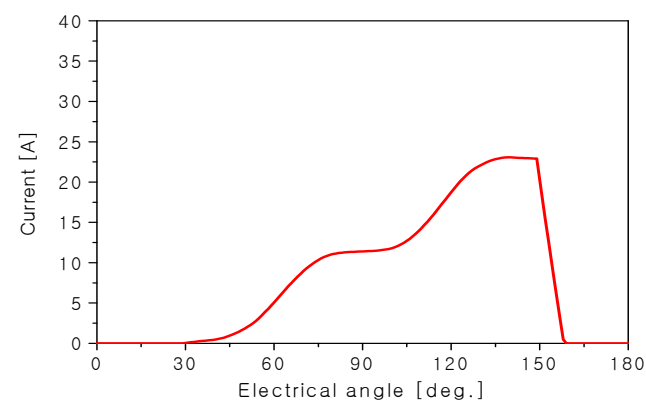

(a) Advance angle $=0^{\circ}$

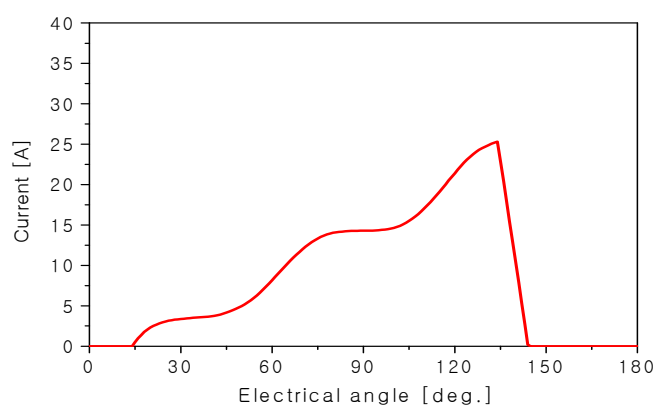

(b) Advance angle $=15^{\circ}$

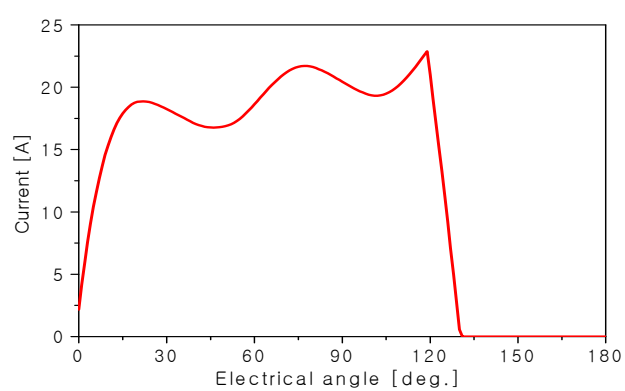

(c) Advance angle $=30^{\circ}$

Fig. 5. Phase current waveforms according to advance angle.

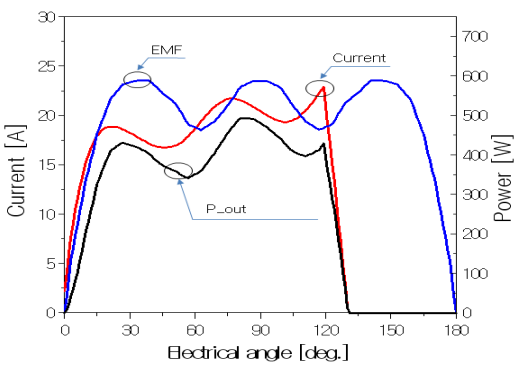

Fig. 6. Output characteristic at a $30^{\circ}$ advance angle.

Fig. 7 shows the average torque based on the advance angle. The average torque is increased due to generation of adequately large currents at the time of the application of a phase voltage to the motor. The current (torque) ripple is reduced and the current amplitude is increased in the $120^{\circ}$ excitation width and $30^{\circ}$ advance angle. Figs. 8 and 9 show the phase current and average torque based on the excitation width. Average torque increases as excitation width rises; at $120^{\circ}$, the torque ripple reaches its minimum.

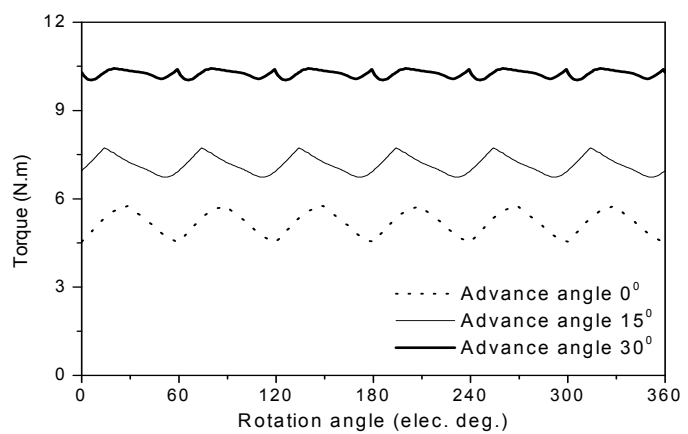

Fig. 7. Average torque according to advance angle.

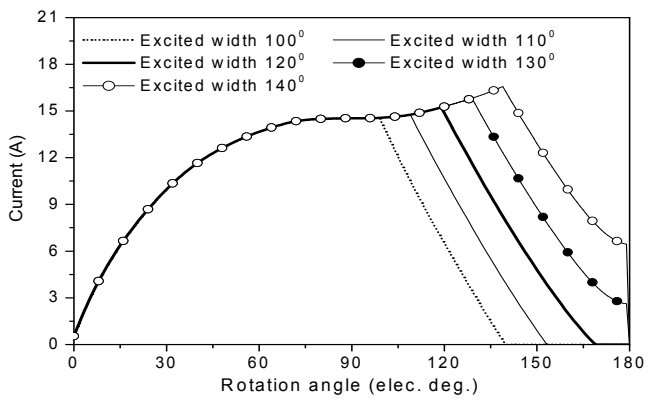

Fig. 8. Phase current according to excitation width.

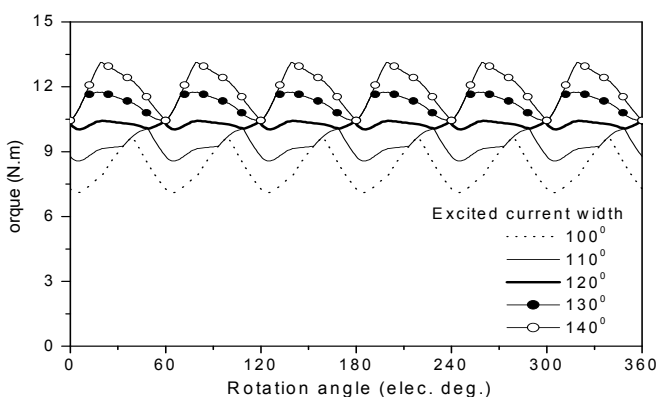

Fig. 9. Average torque according to excitation width. 
Based on the analysis of the results, reducing the torque ripple requires the improvement of current waveform by controlling current advance angle and excitation width. At the advance angle range of $0-30^{\circ}$ and excitation width of $100-140^{\circ}$, and without reaching the reverse torque threshold, the lowest current and torque ripple at a $30^{\circ}$ advance angle and the largest current amplitude at a $120^{\circ}$ excitation width are obtained. Figs. 10 and 11 represent the response curves of motor torque and torque ripple based on advance angle and excitation width based on the results from dynamic current analysis. As shown in Fig. 10, at a $30^{\circ}$ advance angle, generating torque increases as excitation width widens. The $120^{\circ}$ excitation width is deemed most appropriate, considering the reverse torque threshold. Fig. 11 shows the result of the torque ripple analysis. The lowest torque ripple at the $120^{\circ}$ excitation width and the $30^{\circ}$ advance angle are obtained.

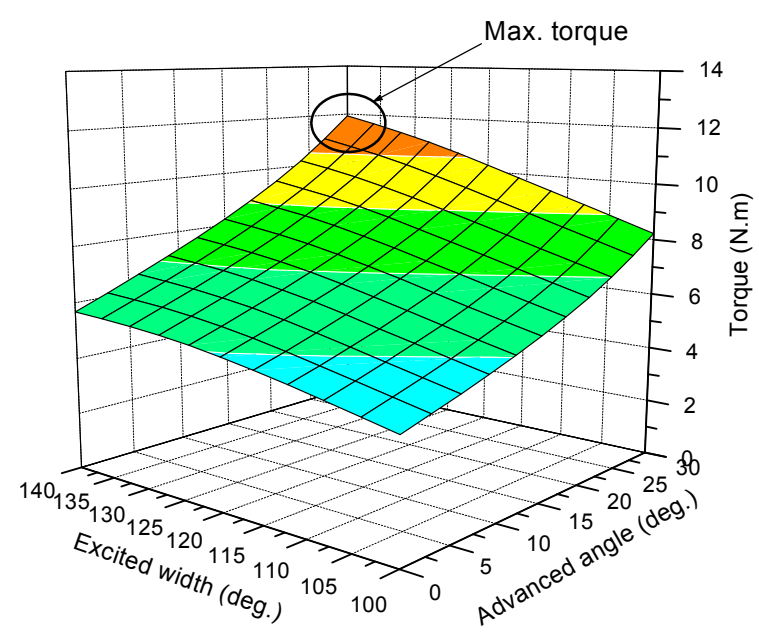

Fig. 10. Surface map of the torque response.

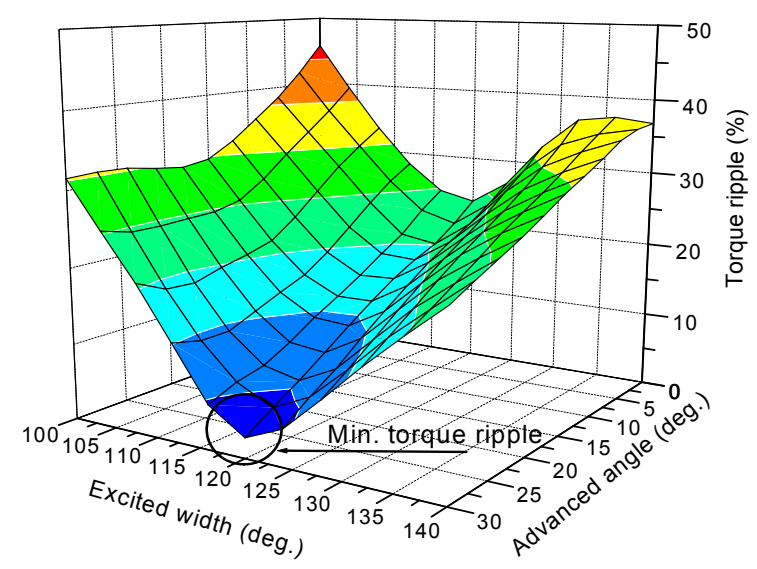

Fig. 11. Surface map of the torque ripple.

\subsection{Design of IEWPM Motor Drive System}

Fig. 12 illustrates the main configuration of the drive system for the IEWPM motor. The drive voltage of this system is DC $48 \mathrm{~V}$, and it is converted into additional voltages (DC $12 \mathrm{~V}$ and DC $5 \mathrm{~V}$ ) with a DC/DC converter used to operate all control circuits. In addition, a low-cost PIC16F73 microcontroller and iM4A5-32 CPLD to reduce design costs are applied in the control system. The inverter's gate signal, which drives the IEWPM motor, is generated from the CPLD's logic design. The microcontroller facilitates the overall I/O control signals for the motor drive system. Speed command is transferred into the microcontroller through the handlebar, which has an embedded magnetic sensor. After performing A/D conversion of potential difference $(0-5 \mathrm{~V})$ generated in the magnetic sensor, the motor's speed command value is adjusted based on its conversion result by controlling the duty ratio of PWM pulse at a frequency of $19.6 \mathrm{kHz}$.

The two-phase excitation method with $120^{\circ}$ conduction angle uses an upper switch PWM mode so that it does not require any dead time in the driving inverter. This could protect the drive circuits from back EMF during sudden braking, providing the motor with a freewheeling path for the inductor current and supplying the system with sufficient current. Fig. 13 shows the operating status of the driving inverter at each interval during a one-cycle operation.

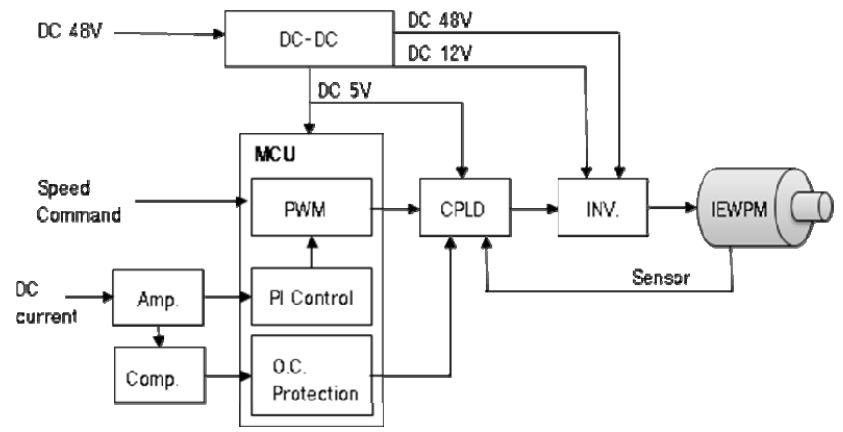

Fig. 12. The main configuration of drive system.
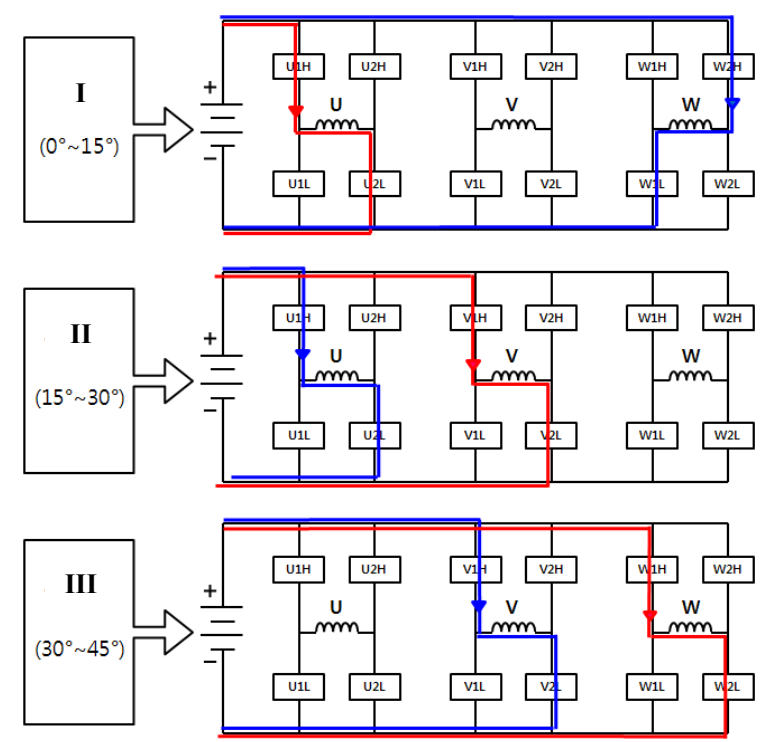

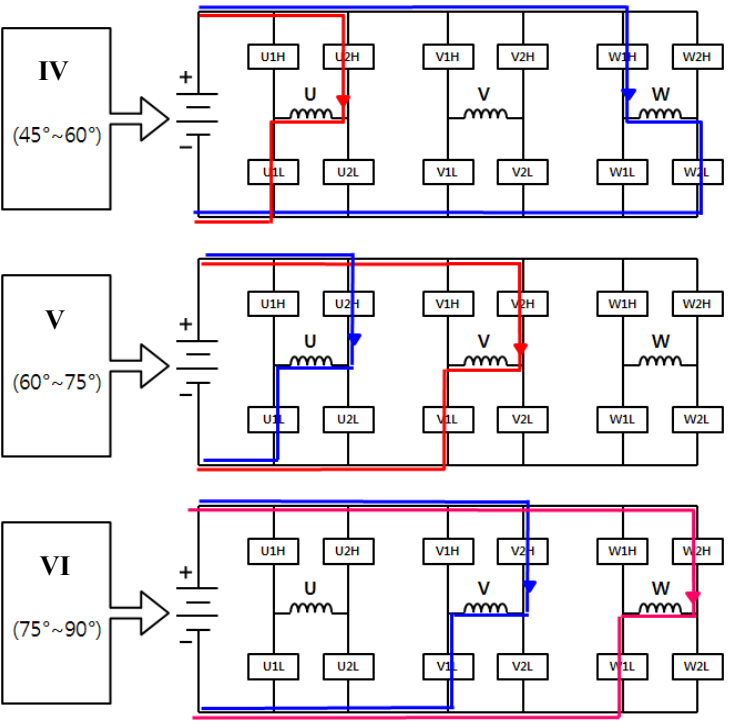

Fig. 13. Inverter drive states in one-cycle operation.

Fig. 14 presents the positional sensor board and shutter installed in the IEWPM motor. As shown in Fig. 14(a), the six sensors are numbered at the sequences of $\mathrm{S} 1, \mathrm{~S} 3, \mathrm{~S} 5$, $\mathrm{S} 2, \mathrm{~S} 4$, and $\mathrm{S} 6$ in a clockwise direction, starting at the angle of $255^{\circ}$ and ending in sensor at an angle of $90^{\circ}$. The sensor board releases only two sensor signals among the six sensor signals at specific times in order to drive the motor. The CPLD releases proper drive signals for the inverter after determining rotor position from the two sensor signals per phase. Specifically, advance angle control is performed by angle adjustment in the sensor board itself. Table 2 shows the operating sequences of the sensor board. Fig. 15 shows the output waveforms from the sensor board at a mechanical rotation of $90^{\circ}$ (quarter revolution) used in the CPLD after inversion.

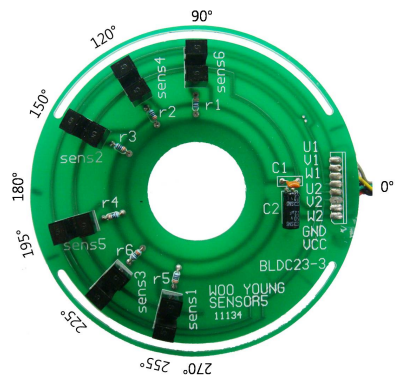

(a) Sensor board

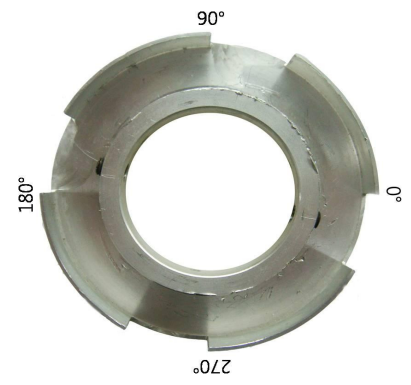

(b) Shutter
Fig. 14. Sensor board installed in IEWPM motor.

Table 2. Operating sequence of sensor board

\begin{tabular}{c|c|c}
\hline Rotation angle & Acting sensors & Output signals \\
\hline $0^{\circ}-15^{\circ}$ & S6 \& S1 & W2 \& U1 \\
\hline $15^{\circ}-30^{\circ}$ & S1 \& S2 & U1 \& V1 \\
\hline $30^{\circ}-45^{\circ}$ & S2 \& S3 & V1 \& W1 \\
\hline $45^{\circ}-60^{\circ}$ & S3 \& S4 & W1 \& U2 \\
\hline $60^{\circ}-75^{\circ}$ & S4 \& S5 & U2 \& V2 \\
\hline $75^{\circ}-90^{\circ}$ & S5 \& S6 & V2 \& W2 \\
\hline
\end{tabular}

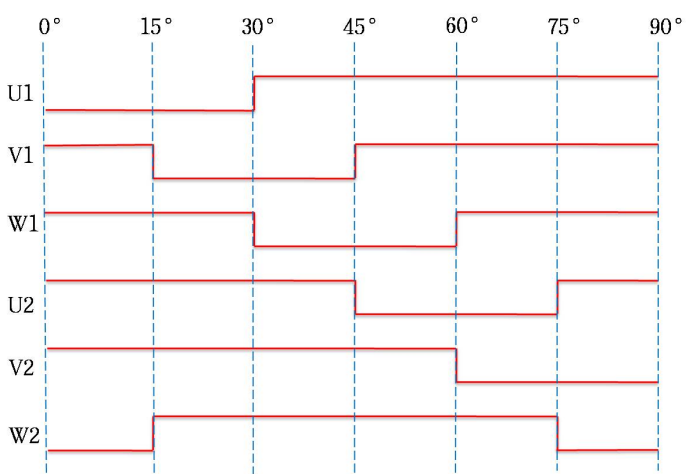

Fig. 15. Output waveforms of the sensor board.

\subsection{Control Software and CPLD Logic Simulation}

The development of control software is implemented using MPLAB IDE ver. 8.14 and an MPLAB ICD2 equipment. The detailed configuration of the drive system for the IEWPM motor is shown in Fig. 16. The flow chart of the control algorithm software for PIC16F73 is illustrated in Fig. 17.

The logic software of the CPLD is developed using ispLEVER Classic v1.2 SP1 for Windows, the ispVM system program, and the ispDOWNLOAD equipment. The principle of the CPLD logic stages for inverter driving (Fig. 18) shows the logic gates of U1H, U2L, W2H, and W1L

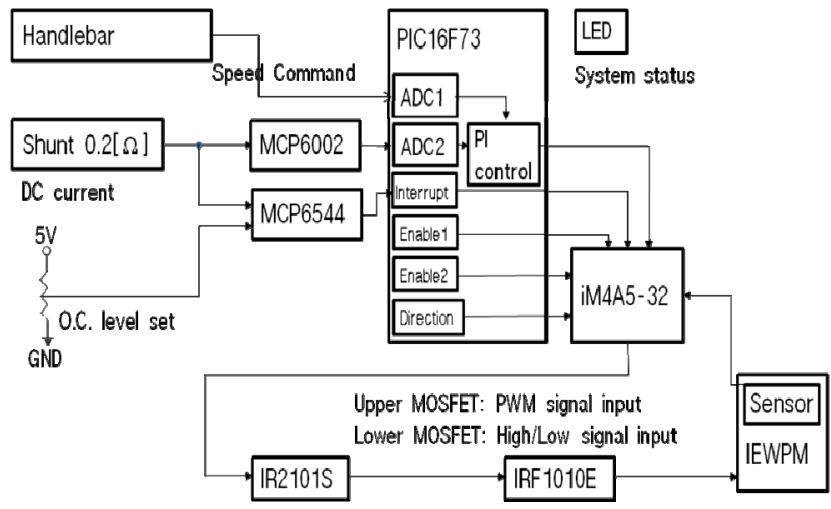

Fig. 16. Detailed configuration of the IEWPM drive system.

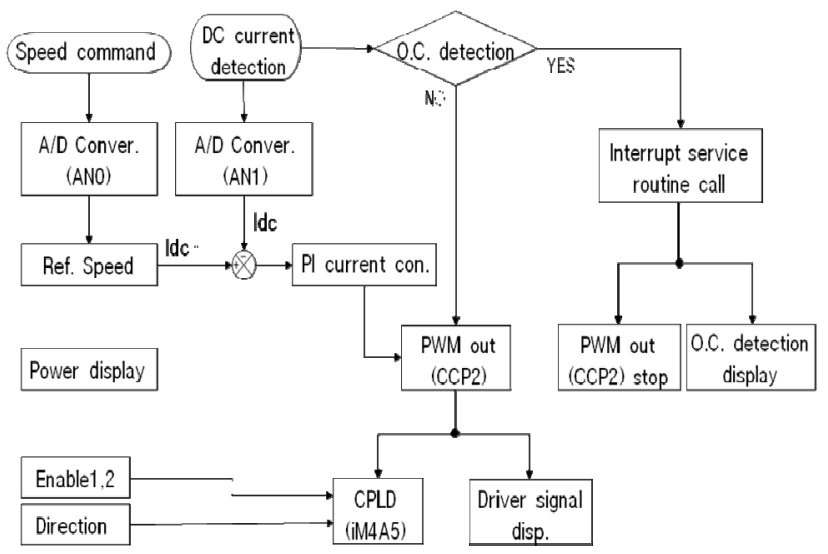

Fig. 17. Flow chart of the PIC16F73 software. 
for the logic stages of the 12 metal-oxide-semiconductor field-effect transistors (MOSFETs). By examining these logic stages and the simulation results (Fig. 19), the output signals of $\mathrm{U} 1 \mathrm{H} / \mathrm{U} 2 \mathrm{~L}$ and $\mathrm{W} 2 \mathrm{H} / \mathrm{W} 1 \mathrm{~L}$ are then determined from the corresponding sensor signals of $\mathrm{U} 1 / \mathrm{U} 2$ and $\mathrm{W} 1 / \mathrm{W} 2$, respectively. In addition, enable1/enable2 logic gates were incorporated to control the upper MOSFETs and the lower MOSFETs separately. The rotational direction of the motor is reversed by a direction signal (high or low) in order to change the output sequences of $\mathrm{U} 1 \mathrm{H}, \mathrm{U} 2 \mathrm{~L}, \mathrm{~W} 2 \mathrm{H}$, and $\mathrm{W} 1 \mathrm{~L}$ signals to the reverse mode.

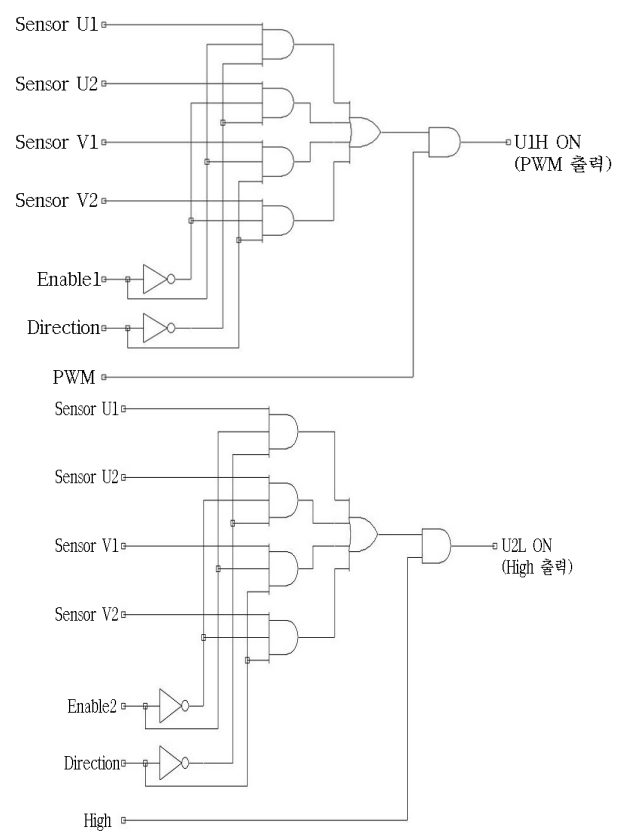

(a) Drive logic for U1H and U2L MOSFET

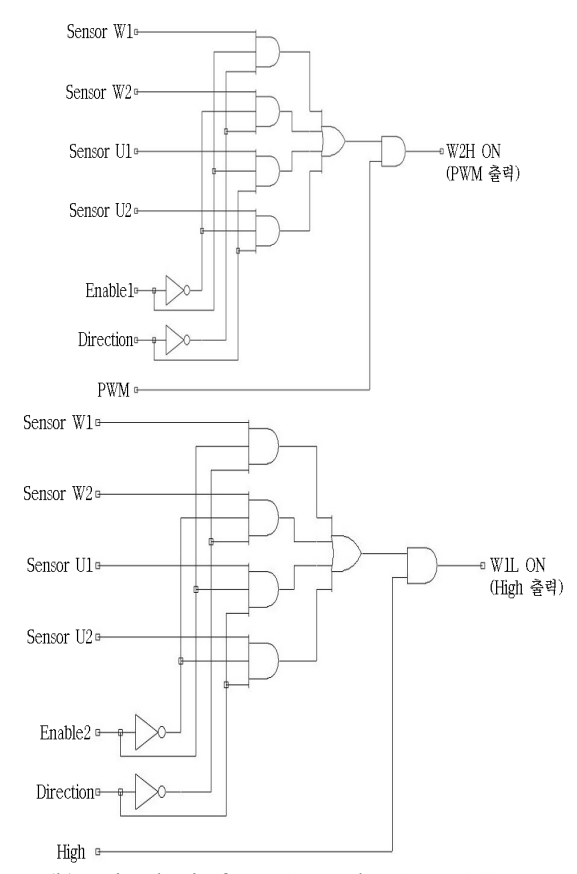

(b) Drive logic for W2H and W1L MOSFET

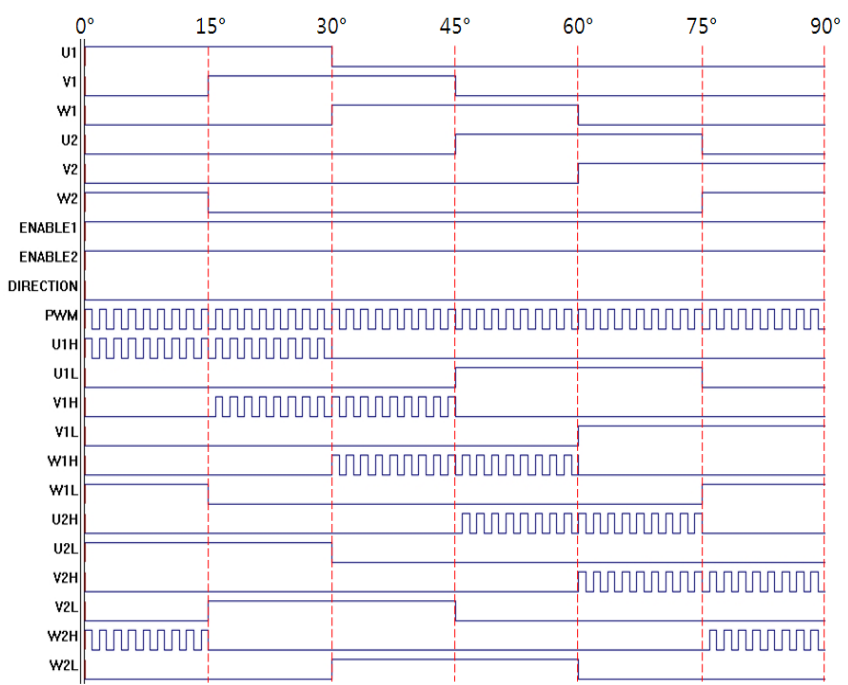

Fig. 19. Operating simulation results of the iM4A5 CPLD.

\section{Experimental Results}

The experimental setup of this paper is shown in Fig. 20, and the designed IEWPM motor and drive system applied to the experiment are shown in Figs. 21 and 22, respectively. Fig. 23 represents the measured waveforms in the CPLD's operating state by using a logic analyzer (TLA720); it verified the simulation results presented in Fig. 19. Therefore, the upper switch PWM mode of the two-phase excitation method applied in this paper operated normally.

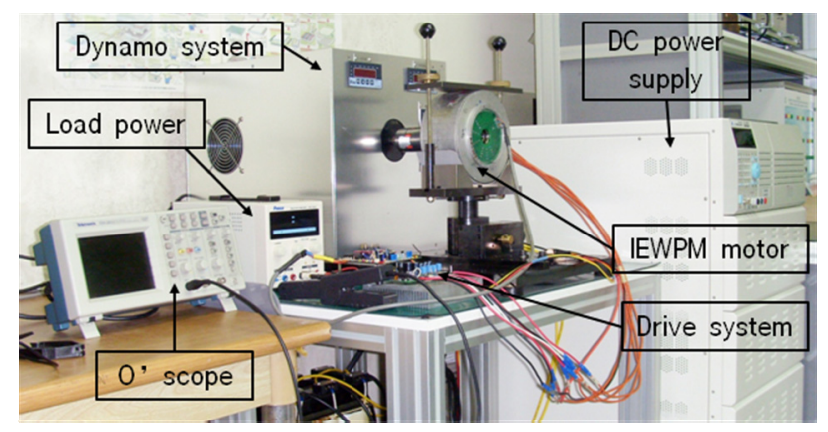

Fig. 20. Load test setup of IEWPM motor drive system.

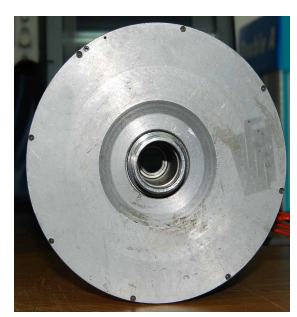

(a) Front side

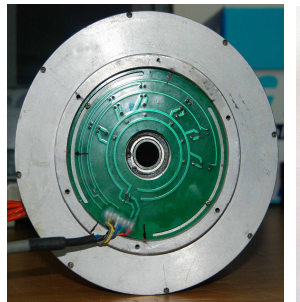

(b) Back side

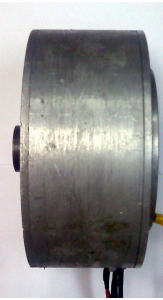

(c) Lateral side
Fig. 21. Outward appearances of the designed IEWPM motor.

Fig. 18. Drive logic for the inverter. 


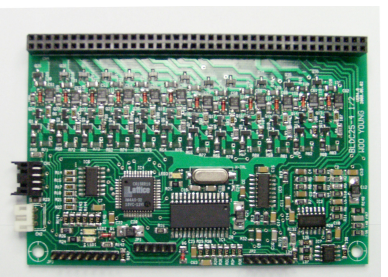

(a) Controller board

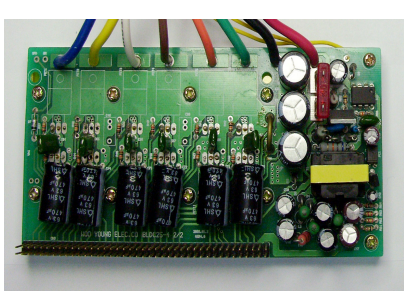

(b) Power board
Fig. 22. The drive system of the IEWPM motor.

\begin{tabular}{ll|}
\hline $\mathrm{D} 3(7)$ & $\mathrm{U} 1$ \\
\hline $\mathrm{D} 3(6)$ & $\mathrm{V} 1$ \\
\hline $\mathrm{D} 3(5)$ & $\mathrm{W} 1$ \\
\hline $\mathrm{D} 3(4)$ & $\mathrm{U} 2$ \\
\hline $\mathrm{D} 3(3)$ & $\mathrm{V} 2$ \\
\hline $\mathrm{D} 3(2)$ & $\mathrm{W} 2$ \\
\hline $\mathrm{D} 3(1)$ & $\mathrm{Enable} 1$ \\
\hline $\mathrm{D} 3(0)$ & $\mathrm{Enable} 2$ \\
\hline $\mathrm{D} 2(7) \mathrm{Direction}$ \\
\hline $\mathrm{D} 2(6)$ & $\mathrm{PWM}$ \\
\hline $\mathrm{D} 2(5)$ & $\mathrm{U} 1 \mathrm{H}$ \\
\hline $\mathrm{D} 2(4)$ & $\mathrm{U} 1 \mathrm{~L}$ \\
\hline $\mathrm{D} 2(3)$ & $\mathrm{V} 1 \mathrm{H}$ \\
\hline $\mathrm{D} 2(2)$ & $\mathrm{V} L$ \\
\hline $\mathrm{D} 2(1)$ & $\mathrm{W} 1 \mathrm{H}$ \\
\hline $\mathrm{D} 2(0)$ & $\mathrm{W} 1 \mathrm{~L}$ \\
\hline $\mathrm{C} 1(7)$ & $\mathrm{U} 2 \mathrm{H}$ \\
\hline $\mathrm{C} 1(6)$ & $\mathrm{U} 2 \mathrm{~L}$ \\
\hline $\mathrm{C} 1(5)$ & $\mathrm{V} 2 \mathrm{H}$ \\
\hline $\mathrm{C} 1(4)$ & $\mathrm{V} 2 \mathrm{~L}$ \\
\hline $\mathrm{C} 1(3)$ & $\mathrm{W} 2 \mathrm{H}$ \\
\hline $\mathrm{C} 1(2)$ & $\mathrm{W} 2 \mathrm{~L}$ \\
\hline
\end{tabular}

Fig. 23. The measured operating status of the CPLD.

Figs. 24 and 25 shows the measured results of the DCside current waveform when a $30^{\circ}$ advance angle is applied and bicycle's handlebar is at its maximum position. Fig. 24 shows the measured results of the DC current with and without PI current control as the motor speed settles into $1000 \mathrm{rpm}$, gradually increasing into the load from the noload state. Fig. 25 shows the measured results of the DC current with and without PI current control $\left(\mathrm{K}_{\mathrm{p}}=\mathrm{K}_{\mathrm{i}}=1\right)$ as the motor torque reaches $4.9 \mathrm{~N} \cdot \mathrm{m}$, gradually increasing into the load from the no-load state. Based on these two results, the PI current control could function more stably and efficiently, such that it has more controllability of the DC current, hence allowing for better torque ripple reduction, unlike in the open loop control.

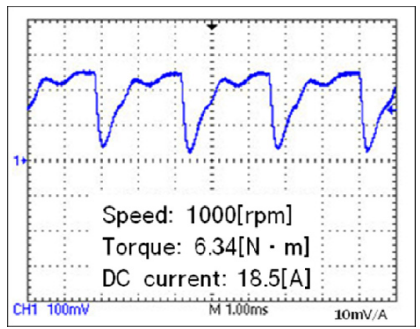

(a) Without PI current control

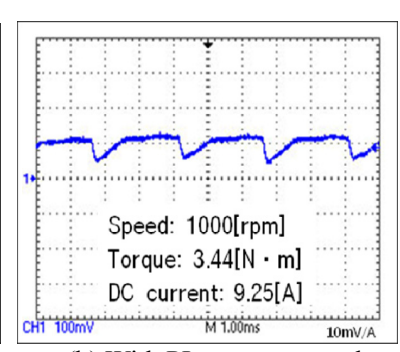

(b) With PI current control
Fig. 24. DC current waveforms (1000 rpm).

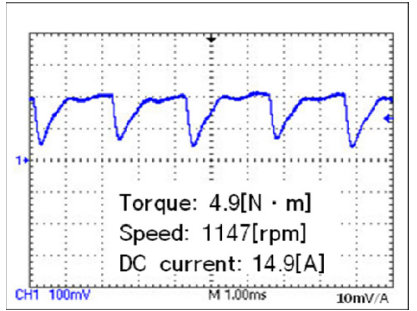

(a) Without PI current control

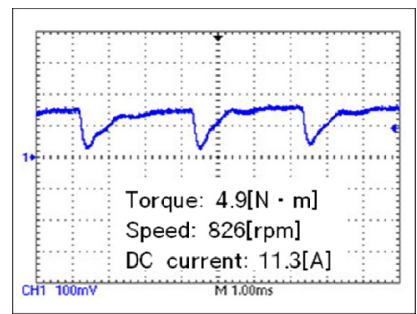

(b) With PI current control
Fig. 25. DC current waveforms $(4.9 \mathrm{~N} \cdot \mathrm{m})$.

Fig. 26 shows the measured waveforms of phase voltage, phase current, back EMF, and DC current with and without the application of $30^{\circ}$ advance angle as the supplied DC current approaches $10 \mathrm{~A}$ for the gradual increase in load. The no-load state experiment resulted in a maximum speed of $1300 \mathrm{rpm}$, torque of $0.16 \mathrm{~N} \cdot \mathrm{m}$, and DC current of $1.6 \mathrm{~A}$ for a $0^{\circ}$ advance angle. For a $30^{\circ}$ advance angle, a maximum speed of $1600 \mathrm{rpm}$, torque of $0.19 \mathrm{~N} \cdot \mathrm{m}$, and DC current of $2.1 \mathrm{~A}$ is obtained. Experimental results (Fig. 26) indicate that the waveform of the phase current for $30^{\circ}$ advance angle is more ideal, and the DC current is controlled in a more stable fashion than in a $0^{\circ}$ advance angle. In addition, system reliability is improved by using the DC-side PI current control and over current protection, apart from implementing the advance angle and excitation width control. Therefore, the motor speed and torque characteristic is improved favorably when DC-side PI current control and a $30^{\circ}$ advance angle is applied.

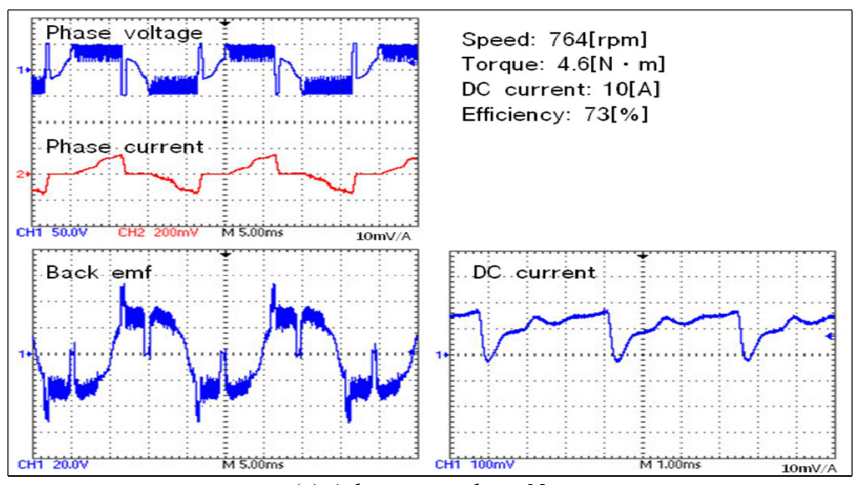

(a) Advance angle $=0^{\circ}$

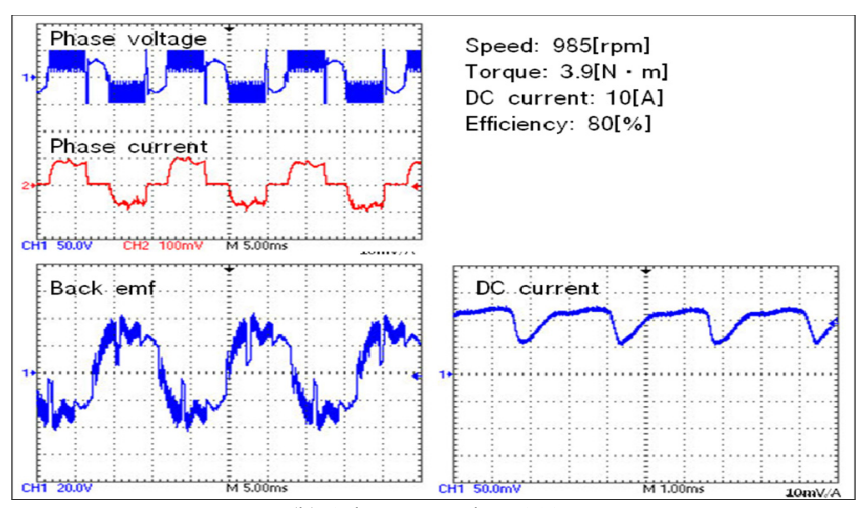

(b) Advance angle $=30^{\circ}$

Fig. 26. Experimental waveforms of motor variables. 


\section{Conclusions}

In this paper, the experimental performances are presented by designing electric bicycle drive system using an IEWPM motor, which is capable of magnifying torque per unit volume using the embedded spoke-type permanent magnet. BLDC motors with Y-connection are mainly applied to electric bicycles because of its broad speed range and simple maintenance. Although the IEWPM motor has superior speed-torque characteristics compared with conventional Y-connection BLDC motors, it has limited applications because of high design costs. This paper offered reliability improvement and cost reduction of the drive system by implementing a DC current controller using a one-chip microcontroller and an inverter-driving PWM logic with CPLD in order to compensate for such a disadvantage. In addition, advance angle and PI current control are designed to improve the efficiency and speed-torque characteristics of the drive system. The experimental results shown in Figs. 24-26 verify these improvements. Consequently, as the IEWPM motor and proposed drive system utilizes simple hardware and software, apart from employing superior operating performance in applications requiring speed or torque control, it could be implemented in various applications of electromotive force, as well as in electric bicycles.

\section{References}

[1] S.K. Safi, P.P. Acarnley and A.G. Jack, "Analysis and simulation of the high-speed torque performance of brushless DC motor drives," IEE Proc.-Electr. Power Appl., Vol.142, No.3, May 1995.

[2] Neil Garcia-Sinclair, "Brushless DC Motor Provides High Power Density and High Efficiency at Low Cost for Electric Transportation," PCIM, Jan. 1996.

[3] J.S. Lawler, J.M. Bailey, J.W. McKeever and J. Pinto, "Limitations of the Conventional Phase Advance Method for Constant Power Operation of the Brushless DC Motor," Proc. of IEEE Southeast Con 2002, pp.174-180, April 2002.
[4] B.-K. Lee and Mehrdad Ehsani, "Advanced Simulation Model for Brushless DC Motor Drives," Electric Power Components and Systems, Vol.31, pp.841-868, 2003.

[5] Kwan-Jun Jo and Jin-Seok Oh, "Characteristic Analysis of Independent 3-phase BLDC Motor," The Trans. of the Korean Institute of Power Electronics, Vol.12, No.4, pp.277-284, Aug. 2007.

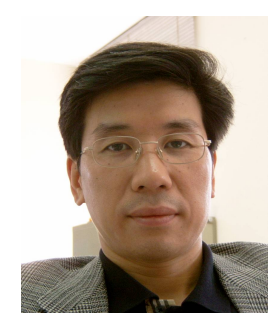

Young-Dae Son received his B.S., M.S., and Ph.D. degrees in Electrical Engineering from Hanyang University, Seoul, Korea, in 1985, 1987, and 1993, respectively. He is presently an associate professor at the Department of Electronic Engineering at Dongseo University, Busan, Korea. From 2003 to 2004 , he was a visiting research professor to the University of South Carolina, Columbia, USA. His current research interests include embedded power electronics, control of electric machines, and intelligent controller applications in power electronics system.

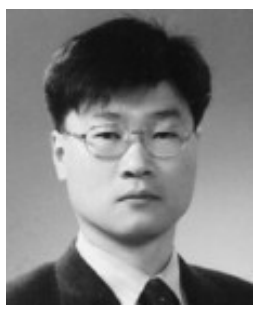

Gyu-Hong Kang received his B.S., M.S. and Ph.D. degrees in Electrical Engineering from Changwon National University, Changwon, Korea, in 1992, 1994, and 2001, respectively. $\mathrm{He}$ is presently a senior researcher at the Electric and Electronic Research Division at Korea Marine Equipment Research Institute (KOMERI), Busan, Korea. His current research interests include the design of high-performance electrical machines, modeling, new concept actuators for special purposes, and the numerical analysis of electromagnetic fields. 